\title{
Apple Products: A Discussion of the Product Life Cycle
}

\author{
Ewa Więcek-Janka \\ Faculty of Engineering Management \\ Poznan University of Technology \\ Poznan, Poland \\ e-mail: ewa.wiecek-janka@put.poznan.pl \\ Martyna Kornecka \\ Faculty of Engineering Management \\ Poznan University of Technology \\ Poznan, Poland \\ e-mail: martyna.kornecka@gmail.com
}

\author{
Miłosz Papierz \\ Faculty of Engineering Management \\ Poznan University of Technology \\ Poznan, Poland \\ e-mail: m.papierz94@gmail.com
}

\author{
Michał Nitka \\ Faculty of Engineering Management \\ Poznan University of Technology \\ Poznan, Poland \\ e-mail: michalnitka18@gmail.com
}

\begin{abstract}
This publication details the life cycles of Apple's mobile products. Its aim is to present their influence on the life cycle of the entire brand.
\end{abstract}

Keywords-Apple; MacBook; iPad; iPhone; product life cycle; brand; sales strategy; marketing strategy

\section{INTRODUCTION}

The literature that first outlined the concept of the product life cycle analysis can be dated to the 1950s. One of the most widely recognized early descriptions of the product life cycle is Levitt's 1965 concept, inspired by biological life, which illustrates the life cycle of a product on the market as a normal distribution of sales volume versus time with four distinct phases: birth, growth, maturity and decline [1].

Kotler [2] says that the concept of the product life cycle can be used by marketers to define the behavior of products on the market as well as the market itself. Additionally, when appropriately used, it can help with choosing the right marketing strategy depending on the life cycle's phase. According to Kotler [2], the concept of product life cycle may concern the product class, product form or a brand. Similarly Wind [3] stated it can be practiced at the product class, form, line or the brand level, whereas Day [4] and Lambkin and Day [5] maintained that the product life cycle is legitimate only at the product class level. Dhalla and Yuspeh, however, argued that the product life cycle can't be considered at any of the mentioned levels in their 1976 work [6]. For Moon (2005) [7], the product life cycle issues can be discussed by using individual brands.

Hofer (1975) [8] considers product life cycle to be the fundamental variable in choosing the right business strategy Similarly, Biggadike in 1981 [9] placed the product life cycle concept in his work amongst the five major contributions of marketing. He theorizes that

product life cycle most importantly "enables marketers to think dynamically", thereby allowing them to predict howstrategies should be modified according to the life cycle's phase. Porter describes the product life cycle as a landmark concept and one of the major theories for predicting industry changes [10].

Smallwood in 1978 [11] noticed that the product life cycle concept can be used in many marketing fields such as: predictions, price strategies, promotions and production planning. He remarked that "in many ways, the product life cycle concept may be considered as the marketing equivalent of the periodic table of elements in the physical sciences". It creates a possibility for grouping products into families in order to predict results to various market stimuli.

Lambkin and Day [5] say that there are few marketing concepts which are so commonly accepted and at the same time criticized aspects of the product life cycle.

In 1976 Dhalla and Yuspeh [6] point out a causality dilemma within the product life cycle. They claim that the shape of the product life cycle's curve is heavily influenced by a manager and their marketing choices, thus it is inconsequential to recommend strategies depending on the phase. Instead they propose usage of marketing communication models. Dhalla and Yuspeh also question the essence and even existence of product life cycle and argue that it " $(\ldots)$ has done more harm than good (...)".

Changes in consumer markets have led to a shortening of market life cycles, as noted and described by Clifford in 1971 [12]. Already then he spoke about companies that ignored the concept of product life cycle when planning marketing strategies of products and noted that the problems will become even more destructive for companies the more life cycles shorten.

Shortening of product life cycles is one of the most prominent changes in the global economy in the last decade. In 2015 Horn [13] stated that fifty percent of the annual income of companies from various market areas comes from products released within the past three years. This fact may suggest that the so-called cash cows (products that have been profitable for a company for 
many years, usually also financially supporting the rest of the company's portfolio) have ceased to exist. The curves of modern product life cycles have changed from flat and shallow to peaked and short lived. According to Goyal the highest percentage of sales occur almost immediately after product's release [14]. Today's market requires replacement of products or services nearly every second year. A company that does not respond immediately to consumers' needs will be replaced by its competitors [15], thereby becoming marginalized in such a rapidly growing market.

\section{METHOD}

To better visualise the influence of Apple's flagship products on the shape of the brand's life cycle, a method of graphical representation was utilised. The data used in the study comes from Apple's quarterly reports and a thorough analysis of the literature on the sales volume of the three most profitable assortment lines and their share of total Apple's sales. The purpose of the study was to determine the influence of the life cycles of three of Apple's flagship products in shaping Apple's life cycle: MacBooks, iPads, and iPhones. ${ }^{1}$

Research focuses on three lines of mobile products: which collectively share $81 \%$ of Apple's profit. Each of them plays a different role in shaping Apple's brand life cycle. This is due to differences in the cost of their financing (one of the main factors is certainly the cost of product promotion), differences in targeting products to other market segments, attractiveness, market competitiveness and dynamics where these products are sold, thus the difference in income from their sales and consequently in the share of each line in the profit of the company.

\section{RESEARCH SUBJECTS CHARACTERISTICS}

iPhone is a line of Apple's smartphones which since 2015 consists of two products, a 4.7" and a 5.5" model named iPhone Plus. Apple's smartphones have an average of lifecycle of 2 years and their new models are usually released once a year (based on models' release dates). The most expensive model is the iPhone 7 Plus costing $\$ 769$ and the cheapest is, released in march 2016, iPhone SE costing \$399. Quarterly sales volume of iPhones has been increasing steadily with the release of each new generation. In the first quarter of 2017, Apple sold 79.3 million iPhones, generating revenue of $\$ 54.4$ billion. Each new device has been becoming more and more popular, and this phenomenon, coupled with a suitably high price for the product, has made the iPhone the most important product in Apple's product range. iPhone's

\footnotetext{
${ }^{1}$ Using the Apple sales literature was necessary to conduct this study, as Apple does not provide detailed information about the sales of its products and their profits' share. For the first few years since the release of the first iPhone, Apple had been providing a summary of the sold items and the profit resulting from their sale for each product line together. The data should be interpreted keeping in mind that sales reports of MacBooks and iMacs are grouped together.
}

success is mainly based on its stylish design, intuitive interface and innovative technology. The iPhone users has become accustomed to Apple's unique ecosystem, but also to the design that ensures social recognition and makes the iPhone, despite its popularity, still a premium product.

iPad is a line of Apple's tablets- touchscreen devices offering functions of phones as well as computers. The iPad line consists of three models: iPad (rebranded to iPad Air in 2013), iPad Mini (smaller iPad version) and iPad Pro (larger iPad version, designer for professionals). Apple tablets have a varied life cycle length starting from half a year (of the imperfect iPad 3) up to 3 years (iPad 2). New models are released around once every year. iPad sales had grown steadily since the third quarter of 2010 (3.27 million units) to the first quarter of 2014 (26.4 million units), after which sales began to fall and in the first quarter of 2017 reached 13.1 million units. iPad prices range between \$1129 (iPad Pro) and \$399 (iPad mini 4). iPads are considered to be easy to use, useful and convenient in all parts of life and fields of work.

MacBook is a line of notebooks that are part of the Macintosh computer line. The line consists of three models: MacBook Retina (classic model), MacBook Air (light and mobile) and MacBook Pro (designed for professionals). Apple laptop products have an average life cycle of 3.5 years, with new models released around once every 1.5 years (calculated using model release dates). Quarterly sales of the Mac family are almost constant and remain at 4-5.5 million units and generate profit of approximately \$5-7 billion per quarter. MacBooks are the most expensive mobile products sold by Apple and their price range falls between $\$ 999$ (MacBook Air 13") and \$2399 (MacBook Pro 15"). MacBooks are positioned in the market as stylish, handy and mobile computers as well as efficient, durable and easy to use.

\section{RESULTS}

The analysis of the sales graphs clearly shows Apple's tendency to regular launching of the flagship models. iPhones are released once a year, about a year after the previous one. The regularity is recognized by customers through smartphone naming that alternates between the classic and the $\mathrm{S}$ versions. The only exceptions to this rule have been the model released in 2013, along with the iPhone 5S, iPhone 5C, and iPhone SE from 2016.

Each iPhone model has a very long life cycle in the market. The longest life cycle belongs to the iPhone $4 \mathrm{~S}$ because long after its release it was still produced in a budget version of $8 \mathrm{~GB}$ capacity. The life span of each model does not depend on the popularity of the device on the market. It shouldn't be affordable for the company to produce and update two older iPhones, but almost every year Apple decides to keep two or three iPhones on the market at the same time. This way, the company continues to be a luxury goods maker, launching smartphones priced above $\$ 649$ (now iPhone 7), but also offering previous generations at a discounted price, typically $\$ 100$ lower compared to the previous iPhone's price as well as those which were supposed to become 
budget versions, even more than $\$ 200$ cheaper (at this time it's iPhone SE for \$ 399). Thanks to this strategy Apple gives the opportunity to buy their unique products to people wanting to spend less money on an iPhone.

A very big jump in the number of sold pieces occurred with the launch of iPhone 6 . The overall design change and diagonal screen size has been very warmly received by the consumers.

The phenomenal success of these devices is reflected in the sales results. Every new device is becoming more and more popular. A change in the life cycle of the product can be seen in the analysis of the sales of the successor of the iPhone 6- iPhone $6 \mathrm{~S}$, which didn't manage to get the same approval from the market as its predecessor. Critics have been speculating about the future of iPhone 7 which after the success of the iPhone 6 and with the radical changes such as the removal of the jack input and introduction of the wireless headphones may not get the same kind of recognition on the market. Nevertheless the iPhone has helped consumers become accustomed to Apple's unique interface, but also to the design that makes the iPhone, despite its popularity, still a premium product.

iPad devices can certainly be considered groundbreaking. It was the first such successful combination of a computer and a phone features that revolutionized the mobile industry. The first iPad 1, released in 2010, has been a great success, with many people wanting to see the convenience and functionality of the device. The life cycle of the first generation is quite short because it was withdrawn with the release of the second generation, a year later. iPhone has come to life of the consumers and has accustomed them to Apple's unique ecosystem, but also to the design that makes the iPhone, despite its popularity, still a premium product.

iPad devices can certainly be considered groundbreaking. It was the first such successful combination of computer and phone features that revolutionized the mobile industry. The first iPad 1, released in 2010.

The iPad 2 has become the model for the next generation in terms of the design and technology. It has been the longest-supported system and also has had the longest life cycle (3 years).

In the third generation released in 2012, the newly introduced high-resolution display showed great promise but it was withdrawn half a year after the launch due to imperfections, which resulted in a negative feedback. The same year another, fourth-generation, was released which fixed the faults of the previous generation making those two models redundant. At this time iPad 2 was still sold on the market offering similar parameters to iPad's 4 but with a slightly worse display.
When the line of full-size iPads had found its place in the maturity stage, they became "cash cows" so Apple could afford to release another line of potential "stars,"the iPad mini. It was released together with iPad 4 and was basically a technological copy of the second generation of the classic iPads in a smaller, more handy version. iPads mini have been released every year since then.

In order to maintain the classic iPad in the profitable maturity phase, it was necessary to refresh the device. Apple rebranded it into the iPad Air (the name suggests lightness and comfort), which helped only for a couple of years and after the release of iPad Air 2 the line entered the decline phase. At the same time, the iPad 2 Mini came out, competing on the market with four other iPad models. It resulted in the highest quarterly sales of 26 million units.

Considering the continuous decline in sales, Apple decided to expand its lineup with a new product line and launched its iPad Pro in 2015. Conspicuously larger than all previous versions, but bringing new possibilities and applications, especially for the professional work. The line is currently in the growth phase. The first classic MacBook was released in 2006 (Fig. 1), another, with the aluminum unibody, two years later followed by the plastic case MacBook, a year later in 2009. The line managed to survive to 2011 (2012 on the education market) and earned the title of the best-selling notebooks. Due to the classic MacBook line's good reputation Apple decided to refresh old MacBooks by giving them new shapes, colors, features and innovative use of modern technology, and released it as one of their flagship products in 2015 .

Apple could have decided to withdraw the MacBook from the market for several reasons. Apple is a company that is well aware of the future market's needs and has adapted to these markets the other two product lines: MacBook Air and Pro. The introduction of the super-slim MacBooks Air and super-powered MacBooks Pro outperformed relatively larger and slower classic MacBooks. It would be difficult to maintain those three lines of the same product on the market, especially when the MacBook was not distinctive enough compared to the rest of the series, therefore it was directed to the educational market, where it also found applaud and faithful followers.

The modern MacBook line has a chance for a success in the market as it was released while the Pro line was at the maturity stage, and the Air line is likely to be in the decline phase. The purpose of introducing such a unique notebook (appearance, parameters and applied technologies) is probably the desire to replace the Air line in the market with a product as innovative as the Air was in 2008 . 


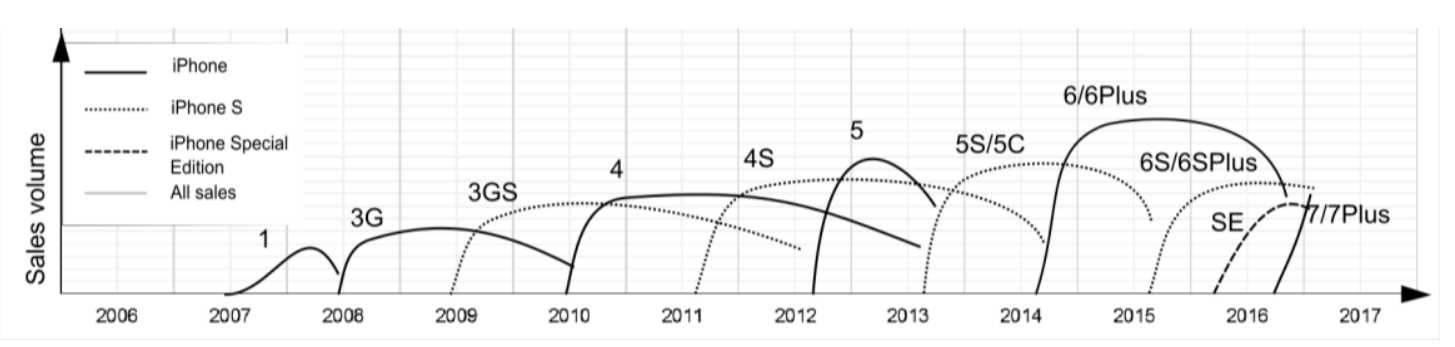

Figure 1. The life cycle of all the iPhone models

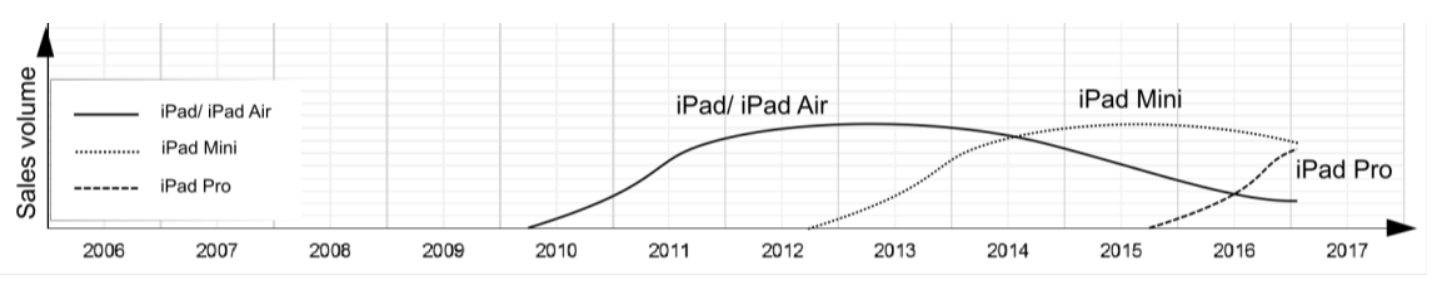

Figure 2. The life cycle of the iPad lines

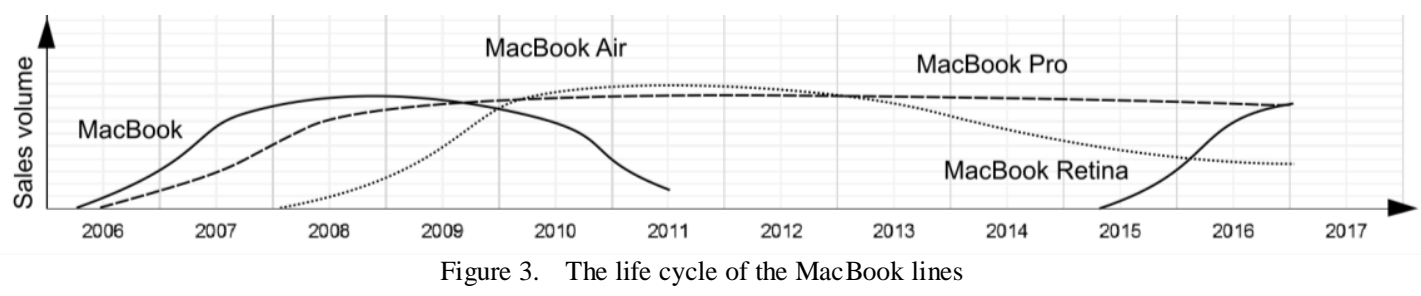

The first MacBook Pro was released in 2006, another revolutionary model- MacBook Pro Unibody- two years later, MacBook Pro Retina after another four years, and the last released model- the MacBook Pro Touch Bar- in 2016. Throughout ten years Apple has released four fairly different models in the same line of notebooks, the first one after two years, the following models every four years. Apple tries to keep this line on the market mostly by regularly releasing revolutionary models. MacBook Pro's marketing is primarily based on the positive opinion among professionals and users of this type of MacBook. MacBook Pro is in the maturity stage and is the longestliving line of Apple notebooks.

The MacBook Air line consists of two distinctive models; the first released in 2008 and the other in 2010. Since then the MacBook Air, after many updates, is still on the market. During its first few years of existence it set the course of the development for other notebooks on the market (as predicted by Jobs). Consumers, Apple fans, and even celebrities were all talking about the incredibly thin and futuristic notebook, providing free advertisement for the product. Since then many more laptops which are thinner and, more importantly, less expensive have appeared on the market. For quite a long time, despite the lack of paid advertising, it was Apple's cheapest "go-to" model, for people who need a fast and portable notebook and want to be the part of Apple's luxury products' users. One of the reasons why MacBook Air did so well on the market could be the fact that between 2012 and 2015 Apple did not release any new notebooks, so the line did not have to compete with the company's own products (like in the case of classic MacBooks and Pro). The most recent update of the MacBook Air was held in early 2015. Waiting for a hardware upgrade for almost two years is not common for Apple, which updates its hardware at least once a year. The release of the new line of even thinner, even more beautiful and even more powerful MacBooks (Retina) should decrease MacBook Air's sales even more. Apple does not try to rescue this line, but instead focuses on the more promising refreshed, classic and professional MacBooks. The Airseriesis in the declinestage.

\section{CONCLUSION}

The life cycle of the discussed products is two to three years for the iPhone. The first generation of Apple's smartphones was sold for only one year after its introduction to the market. The company's decision to quickly withdraw the first, weak and faulty version of the phone, and to launch another, improved model at the same time of the withdrawal of the previous one, proved to be the key to the success of this product. iPhone $3 \mathrm{G}$ and the next generation 3GS, thanks to their reliability, have created a brand for themselves and gained many loyal customers (which proved to be crucial for Apple's marketing purposes). The $3 \mathrm{GS}, 4$ and $4 \mathrm{~S}$ models remained on the market for three years, battling for customers with their predecessors and successors. An interesting moment in the marketing of Apple's products was the release of iPhone 5, which was at that time the best-selling iPhone, 
and taking it out of the market just after a year. This was a planned operation designed to prepare consumers market for the next two models: $5 \mathrm{~S}$ and the multicolour $5 \mathrm{C}$. The next three models of $5 \mathrm{~S} / 5 \mathrm{C}, 6$ and $6 \mathrm{~S}$ remained on the market for two years.

The life cycle of iPads range from six months (iPad 3) up to three years (iPad 2 and Mini 2). The strategy of a quick withdrawal from the market is understandable in the case of the first iPad (which after gaining acceptance among the customers quickly needed another model fixing all of the first version faults) and iPad 3, another of Apple's technological setbacks, replaced in half a year's time by iPad 4. A rather unusual operation was the release of the 2014 iPad 3 Mini, which was an almost unchanged version of its predecessor and was replaced by an improved model- iPad 4- after a year. It would seem that the release of the third Mini version was only provisional, aimed at maintaining Apple's regular market penetration with new products. The optimal lifespan of an iPad on the market lasts about two and a half years. The classic iPad line, which was rebranded in 2013 and has changed its name to iPad Air, has begun its seventh year on the market, but the chart analysis indicates its future withdrawal. The empty space on the market will be therefore taken by the Pro line. Currently it is in the growth phase being little over one year old. The iPad mini line has been on the market for more than four years, and the life cycle curve points to the decline stage. Apple probably does not intend to release any further iPad Minis, so it's likely that the brand will "die" over two consecutive years or be rebranded to the iPad Mini Pro.

For a long time MacBook Air and MacBook Pro were, according to the BCG matrix, Apple's "cash cows". Despite the position of the MacBook Air at the stage of decline, it cannot be said that it is the company's "dog". Sales, though not growing, are sufficient enough to fund the series itself and to support products that require more marketing effort that Air does not need anymore. The new MacBook definitely fits the definition of a "question mark", which is close to becoming a star if Apple follows the success with a good update, but it can also become a failure when the update does not offer consumers anything better than already exists on the market.

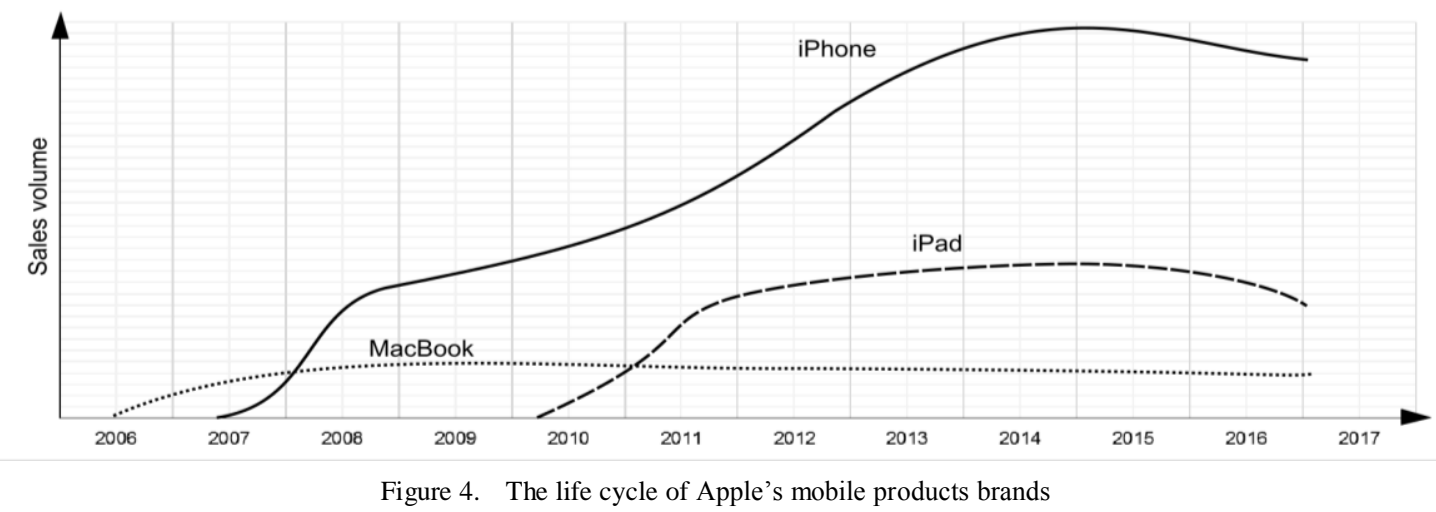

The strategy for product lines of iPhone is to introduce new models to the market not only in the growth phase, but throughout their maturity stage. This causes a directresponse in market because of the activation of the loyal customers who cannot afford to miss the latest model and need to be up-to-date with the new technology. In this phase prices are unchanged, each next released model is sold at the same or even higher price than its previous version. The maturity phase brings smaller, lighter, more efficient models of products to the market and makes them available in a variety of colors. It's easy to see Apple's product development has changed from making only black and white products to a brand that has invented its own unique color names for marketing purposes. In the maturity phase not only does the price increase, but also the quality and quantity of the offered services which makes the maturity stage longer and therefore provides the company with a steady income. Marketing at this stage is based on whisper marketing, sponsorship (iPads and MacBooks in education) and in some cases product placement. At the end of the saturation phase Apple decides to introduce another product line (iPad Pro in the saturation phase of the iPad and MacBook Retina in the saturation phase of the MacBook Air) to capitalize on the "cash cow's" financial potential for funding the rest of the products in the lines. Apple does not try to keep all product lines on the market at all costs. Seeing their sales decrease, it does not release any new models, but instead focuses on the development of the other products from the product range.

The curves of the brand life cycles show the need that Apple has had for two years to retain its reputation as an innovator on the market, activating new customers, and encouraging loyal customers to buy its products by introducing brand new products with new names, look or features (like iPad Pro, MacBook Retina, MacBook Pro Touch Bar and iPhone SE). By analyzing the data, we can say that MacBooks, iPhones and iPads as brands have fairly long life cycles (eight to ten years) especially considering the rapidly changing electronics market. It seems though that the downturn is unavoidable, as sales data confirm: iPhone sales have been going down since the release of iPhone 6S, alongside decreasing quarterly sales of iPads, and the inevitable withdrawal of MacBook Air from the market. Apple is aware of this and therefore focuses on the promotion and development of the new 
product line, the Apple Watch. However, it is certain that Apple should be able to maintain its flagship products on the market for the next several years, providing customers with innovative solutions and beautiful design.

\section{REFERENCES}

[1] T. Levitt, "Exploit the product life cycle," Harvard Business Review, vol 43, November-December 1965, pp 81-94.

[2] P. Kotler, and G. Armstrong, "Principles of Marketing," 15th Global edition, Upper Saddle, N.J.: Pearson, 2014, pp. 273-279.

[3] Y. J. Wind, "Product Policy : Concepts, Methods, and Strategy," Reading, MA: Addison-Wesley Publishing Company, 1982, pp. 49.

[4] G. S. Day, "Analysis for strategic market decisions,." St Paul, MN: West Publishing Company, 1986, pp. 61.

[5] M. Lambkin and G. S. Day, "Evolutionary processes in competitive markets: Beyond the product life cycle," Journal of Marketing, 53, 1989, pp. 4-20.

[6] N. K. Dhallan and S. Yuspeh., "Forget the product life cycle concept," Harvard Business Review, Jan-Feb 1976, pp. 102-112.

[7] Y. Moon, "Breakfree from the product life cycle," Harvard Business Review, 83(5), 2005, pp. 86-94.

[8] C. W. Hofer, "Towards a Contingency Theory of Business Strategy," Academy of Management Journal, 18 (December) 4, 1975, pp. 784-810
[9] E. R. Biggadike, "The Contributions of Marketing to Strategic Management," Academy of Management Review, 6 (October) 4, 1981, pp. 621-632.

[10] M. E. Porter, "Competitive Strategy: Techniques for Analyzing Industries and Competitors," New York: The Free Press, 1980, pp. 157.

[11] J. E. Smallwood., "The Product Life Cycle: A Key to Strategic Marketing Planning," MSU Business Topics, 21 (Winter),1978, pp. 29-35.

[12] D. K. Clifford, "Managing the Product Life Cycle," The Arts of Top Management, New York: McGraw Hill, 1971, pp. 216-226.

[13] K. Horn, "The Product Life Cycle is in Decline", retrieved March 20, 2015 from http://www.sourcingfocus.com/site/opinionscomments/the_product _life_cycle_is_in_decline/.

[14] T. Goyal, "Shortening Product Life Cycles?," retrieved March 20, 2001 from http://www.edn.com/electronicsnews/4356514/Shortening-Product-Life-Cycles.

[15] J. Trojanowska, K. Żywicki, E. Pająk, "Influence of selected methods of production flow control on environment", in: Information Technologies in Environmental Engineering, (ed.) P. Golińska M., J. MarxGomez, Springer, 2011, pp.695-705 DOI: 10.1007/978-3-642-19536-5_54. 